\title{
He was a boy with a name
}

CMAJ Podcasts: article reading at https://soundcloud.com/cmajpodcasts/160530-hum

$\mathrm{A}$ head pops up out of a large trash can on the other side of the street. I know that head: five days ago I had seen it lying in a pool of blood. His eyes dart this way and that and then meet mine. A smile spreads across his filthy face.

\section{Five days before}

I was pleased with myself. I'd picked up the hints my daughter had dropped and was loaded down with her birthday presents as I walked to my exwife's apartment to deliver them. I held bags filled with things she didn't need but would probably love.

I walked beside a road full of cars that jostled and pushed; the arteries of Beirut on a Tuesday evening are always clogged. Bored, frustrated drivers "whatsapped," "facebooked" or leaned on their horns. I drowned out their noise with music blasting through earphones lodged firmly in my head.

A harrowing cry pierced the music and my head snapped sideways.

I saw a crowd gathering at the base of some untidy scaffolding pushed up against a building. A circle had formed around something. A woman stepped away, her head shaking from side to side, her hands on her cheeks, an anguished look on her pale face. In the space she left, I saw a small person lying still on the sidewalk. I pushed through the snarling traffic and entered the circle.

I looked down and saw a boy, maybe eight years old. He was motionless; face down, holding his knees, a halo of blood spreading steadily and silently away from his head. I heard mutterings in Arabic of "fall" and "scaffold," and I looked up and wondered how far he had fallen and why he was up there in the first place.

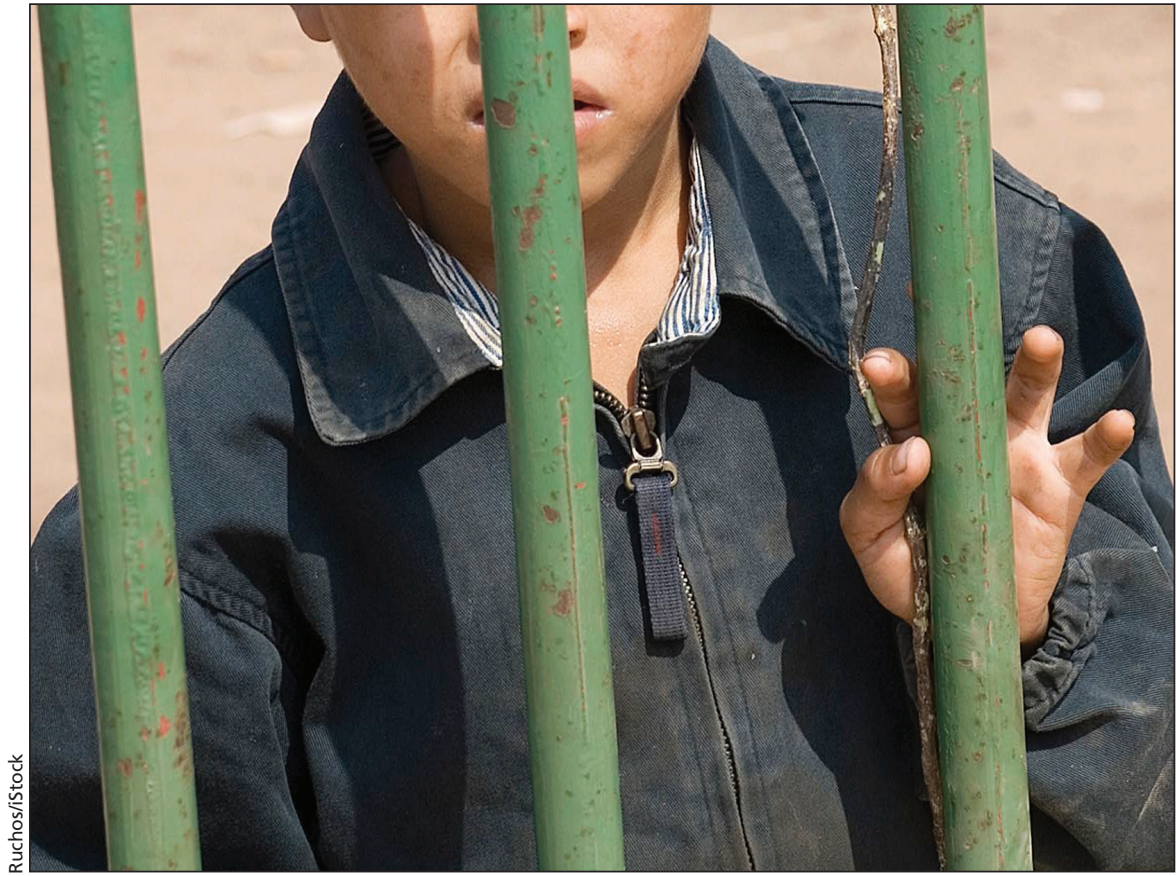

I announced, "Ana hakim." I'm a doctor. But I stood with gift bags in hand, frozen. A-B-C-D-E was ringing loudly in my head - A, airway; B, breathing — but I felt paralyzed holding those bags.

Next to me was the chocolate shop. The owner knows me and always slips in extra treats whenever I spoil the kids with something sweet. I shoved open the doors and pushed the bags into his hands and said, "Look after these, thanks!"

I knelt next to the boy, the holes in his clothes and the dirt on his skin declaring him a refugee. He was breathing, he was holding his knees and rocking ever so slightly; all good signs. Someone asked, "Hakim, should we call an ambulance?"

I looked through the legs of the people around me, saw the stationary cars, heard their horns and remem- bered the traffic. It would take an hour to get to the hospital, although it was only 200 metres away. Risking injury to the boy's spinal cord, I pushed my arms under his shoulders and legs and scooped him up, the circle dissolved and I was alone with the boy.

As I walked, all I heard were my steady, laboured breaths. I looked down at the boy; I saw the lacerations on his lips and face and saw his front teeth, smashed and broken. He moaned softly and turned his head toward me. Through his pain and fear he must have seen my blue eyes, my Western face; I couldn't imagine what he thought. Blood dripped down onto his neck, soaking his T-shirt and making a burgundy collar.

As I dropped him onto the stretcher in trauma bay two, the system took over: nurses got vitals, my colleague came into the room and started to talk 
to the boy while making sure his neck wasn't injured. As he pressed on the bones of his spine, he asked "Shu ismak?" What's your name?

\section{"Mahmoud."}

Of course he had a name, but now I knew it. He wasn't a Syrian refugee anymore; he wasn't one of 1.2 million in Lebanon; he wasn't a street kid; he was a boy with a name.

I stepped back as the team took over. They did a physical exam, looked at his lacerated lips, rolled in the ultrasonography machine so that they could check for internal bleeding and started ordering X-rays.

It was time for me to leave. I went to Mahmoud and told him in my faltering Arabic that he was going to be okay and that everything would be fine. I slipped a Lebanese 10000 -pound note, about six dollars, into his bloodstained hand and left.

My daughter loved her presents and we spent a half hour chatting and laughing, with my two sons joining the impromptu party. I was distracted though and, after a while, I told them about Mahmoud. They stared transfixed as I described what had happened. "Is he going to be all right?" asked my eldest son, Rashad.

"I think so," I said, "I'll check on him on the way home." The story made our celebrations somber, and we grew quiet.

Mahmoud was still in trauma bay two, but now he was crying and looking frightened.

"Shu habibi, lay am tibki?" Why are you crying? I put my arm around him. He moved closer and seemed to try to hide in my armpit. I asked a nurse what was going on.

"Hakim, we have to call the police because it's a fall from a building. He's frightened because if his dad finds out he's caused trouble, he will beat him." I looked at Mahmoud's tear-streaked face, the salt water pushing shiny lines through the dust covering his skin.

I found the resident looking after Mahmoud's case.

"Karim, we should call the childprotection person on call." Fadi, a children's psychiatrist, answered.

All Mahmoud's x-rays were fine, the ultrasonography didn't show any bleeding, and the cuts on his face and lips had been cleaned, sutured and dressed. We took him into a small room off the main emergency room and Fadi started to talk to Mahmoud.

Fadi was great; in no time, he had Mahmoud chatting and opening up. I tried to follow, but the speed of their conversation and Mahmoud's Syrian accent made it difficult. At one point, I knew Fadi was asking Mahmoud where his home was and how he was going to get there tonight. I thought I heard Mahmoud say he couldn't go home before 10. Fadi looked away from Mahmoud and looked at me with dismay, his head shaking slowly. 10 ?"

"What? He can't go home before

"No," Fadi said slowly, "he can't go home before he gets another 10000 pounds. He has to bring back 20000 every day or he can't go home."

We stared at each other, both lost in the awfulness.

I thought about my children and the luxury of our existence. I must have walked past 10000 begging Syrian children on the streets of Beirut, trying not to be touched by their grimy hands as they reached out asking for money, asking for kindness. Sometimes I give, more often though, it's too much; there are just too many and they all become one, and it's easier to listen to my music and escape.

Fadi and I reached for our wallets. We pulled out notes and handed them to Mahmoud. He thanked us without making eye contact.

\section{Five days later}

The weekend is over, and it is time to take my kids back to their mom's apartment. As we walk, I see Mahmoud inside the trash can.

As he climbs out, I turn to my kids and tell them whom they are about to meet. Mahmoud comes to me smiling, dragging a large cardboard box behind him.

"Keefak?" How are you?

"Mneh." I'm good, he replies.

I point: "Wlede," my children, "Rashad, Maysoun, Siraj."

"Marhaba." Hello, he says, shaking their hands in turn in a formal, dignified way.

After a short chat we say goodbye, and I continue on my way with the kids.

"He seems nice," says Siraj, my youngest, as he walks next to me, holding my hand.

"Yes, he does, doesn't he," I reply. I lift his hand and kiss it.

"Is he going to be able to go home tonight Dad?" asks Rashad.

I look back as Mahmoud drops the cardboard box next to a couple of others that are already flattened out; he is making his bed.

\section{Nicholas Batley MD \\ American University of Beirut Medical Center, Beirut, Lebanon}

This article has been peer reviewed.

This is a true story. The patient's name and personal details have been changed to protect their identity.

CMAJ 2016. DOI:10.1503/cmaj.160530

"Wherever the art of medicine is loved, there is also a love of Humanities." - Hippocrates 